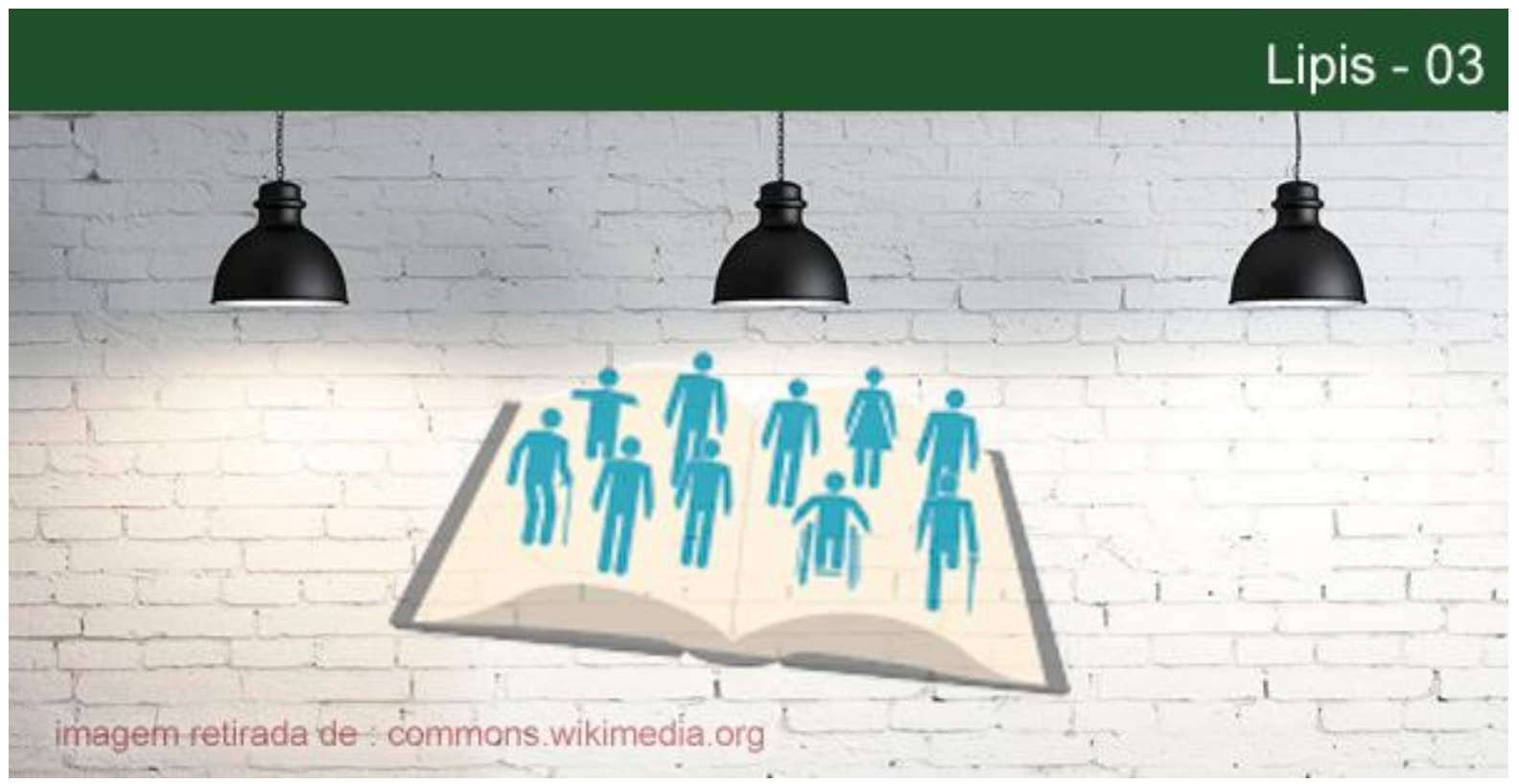

\title{
A EDUCAÇÃO INCLUSIVA EM TEMPOS DE JUDICIALIZAÇÃO DO ESTADO: O COTIDIANO DAS ESCOLAS COM A LEI BRASILEIRA DE INCLUSÃO - $\mathbf{N}^{\circ}$ 13.146/2015
}

\author{
Dayse Serra \\ Professora Adjunta de Educação Especial e Inclusiva na Universidade Federal Fluminense (UFF), Doutora em \\ Psicologia Clínica pela Pontifícia Universidade Católica (PUC-Rio), Vice-Presidente da Abenepi - Associação \\ Brasileira de Neurologia e Psiquiatria - capítulo Rio. Psicopedagoga Especializada em TEA (Transtorno do \\ Espectro Autista). E-mail: dayseserra@yahoo.com.
}

Resumo: Este artigo pretende analisar o cotidiano das escolas após a implementação da Lei Brasileira de Inclusão, a Lei $n^{\circ} 13.146 / 2015$. É possível observar no documento orientações sobre os critérios de avaliação do aluno com deficiência, orientações sobre matrícula nas redes de ensino e alterações de direitos civis. $\mathrm{O}$ tema mais nevrálgico da lei no cenário educacional e recorde de ajuizamento de processos foi, por parte das instituições privadas e ainda tem sido por parte das famílias, a mediação escolar. Há avanços, retrocessos e pontos obscuros no campo da educação com a nova lei, sendo necessário que se faça a análise de sua aplicação nas escolas um ano depois de ter sido instituída e quatro meses após o prazo que as escolas receberam para se adaptar aos novos parâmetros.

Palavras-chave: Legislação. Inclusão. Mediação.

\section{THE INCLUSIVE EDUCATION IN TIME OF JUDICIALIZATION OF THE STATE: THE DIALY OF SCHOOLS WITH THE BRAZILIAN LAW OF INCLUSION - No 13.146/2015}

Abstract: This article intends to analyze the daily life of schools after the implementation of the Brazilian Inclusion Law, the Law $\mathrm{n}^{\circ} 13146 / 2015$. It is possible to notice in the document: guidelines on the evaluation criteria of students with disabilities, guidelines on how to enroll for education networks and changes of the civil rights. In the educational setting, the most important issue of the law and a record of filing lawsuits has been the school mediation; not only by private institutions but also by families. There have been advances, setbacks and unclear points in the field of education with the new law, which requires an analysis of its application in schools a year after it was established and four months after the deadline schools received to adapt to the new parameters.

Keywords: Legislation. Inclusion. Mediation.

\section{POLÊM!CA $\mid$ LABORE (}

Polêmica - Revista Eletrônica da Uerj - Rua São Francisco Xavier, 524, $1^{\circ}$ andar

bloco D, sl.1001 • Tels.: +55 21 2334-4088 / 4087 • http://www.e-publicacoes.uerj.br/index.php/polemica/index

http://www.labore.uerj.br • laboreuerj@yahoo.com.br 


\section{Introdução}

Quando pensamos em inclusão, pensamos em igualdade de direitos e no ingresso de um aluno com necessidades educacionais no contexto escolar com aprendizagem, desenvolvimento e participação. Este é o nosso desejo, mas não tem sido sempre assim. As escolas regulares têm sido lugar de conflitos pelos desafios impostos a cada dia. De um lado os familiares falam da recusa da matrícula, das angústias em relação ao futuro e das dificuldades que encontram em relação ao acompanhamento da aprendizagem dos seus filhos. O quanto podem receber as avaliações da aprendizagem como uma resposta fidedigna ao processo didático e muitas dúvidas sobre métodos, técnicas e metas a alcançar. De outro, profissionais que não se sentem preparados para atuar no campo das deficiências, termo usado pela Lei Brasileira de Inclusão, que passou a vigorar em $1^{\circ}$ de janeiro de 2016 . Além das dificuldades no cotidiano, os profissionais de educação também falam do número de alunos, da formação insuficiente para elaborar planos educacionais e adaptar as atividades de maneira que tenham um mínimo de certeza de estar no caminho certo. Os apoios surgem de forma muitas vezes improvisada, criando mal-estar nas escolas. Neste cenário surge o mediador, ponto quase central nas discussões quando a nova lei passa a vigorar. Diante de tantos conflitos, começamos o semestre de 2016 sob a forma da lei, com inúmeros conflitos e com a judicialização da educação.

Este artigo teve o objetivo de analisar o impacto da Lei Brasileira de Inclusão (13.146/15) nas escolas regulares e analisar em especial as discussões sobre mediação escolar, identificação das necessidades educacionais especiais e as práticas pedagógicas.

\section{A inclusão escolar no centro dos conflitos}

Em julho do ano de 2015, foi instituída a Lei Brasileira de Inclusão, a lei n ${ }^{\circ}$ 13.146. Mesmo com existência de muitos documentos legais como portarias, decretos e deliberações, havia um brado entre familiares e educadores por um documento que formalizasse as práticas da inclusão educacional. As queixas sobre negação de direitos e validade da educação inclusiva vinham de todos os lados, pois familiares e profissionais sempre se sentiram desnorteados sobre como operacionalizar o cotidiano, de modo que a aprendizagem e o desenvolvimento de seus filhos e alunos pudesse realmente justificar a frequência na escola, denominadas no âmbito da inclusão de escola regular.

\section{POLÊM!CA $\mid$ LABORE}


Em tempos de judicialização de diversos setores sociais, parece que como cidadãos, ainda não aprendemos a resolver os conflitos de outra forma. Diante de culturas de estigma, preconceito e discriminação, entregamos, mais uma vez, as decisões sobre as formas de existir, definições de regras para funcionamento da saúde, educação e direitos, para o judiciário decidir normas e conteúdo. Na esfera da educação, as dificuldades são tão intensas e desafiadoras que os saberes que habilitaram os educadores durante as suas formações e a formação continuada, não dão conta da demanda da diversidade no contexto da escola. Criamos, com nossas práticas equivocadas, "várias escolas" dentro de uma mesma instituição, e acreditamos que estamos assim, praticando a inclusão. Muito provavelmente, se as escolas tivessem os seus projetos político-pedagógicos como norte para as suas próprias práticas, não falaríamos em Educação Especial ou Educação Inclusiva. Uma única educação, praticada em todas as escolas, daria conta da diversidade de cada aluno, pois educar um sujeito no campo das suas diferenças já faria parte do cotidiano das instituições.

Ao afirmarmos que a escola é inclusiva, podemos não ter plena consciência, mas afirmamos que fomos preparados para educar os "iguais" ou os "típicos" (nome politicamente correto para nomear o que antes a sociedade chamava de "normal"), mas abrimos uma exceção para receber os que possuem uma diferença física, cognitiva, sensorial ou de qualquer outra ordem.

A presença de um aluno com deficiência no ambiente escolar, tal qual como ele está estruturado, provoca muitos desafios em boa parte das instituições escolares. Nosso formato de sala de aula e de escola é extremamente antigo, não necessariamente ultrapassado. Nas escolas com propostas pedagógicas não tradicionais, encontramos salas de aula com quadros de escrever, carteiras, mesa de professor e mesa de alunos, trabalhos em papéis timbrados, livros didáticos, sistemas de avaliação com calendário e conteúdos para estudar para a prova, sistemas de ensino unificados e terceirizados, e a presença de personagens que ensinam e outros que aprendem. Tudo é familiar e antigo, menos a inclusão que parece mais recente e inédita a cada dia, sublinhando as dificuldades das escolas com o tema. Escolas tradicionais e não tradicionais, públicas e privadas, relatam suas dificuldades para gestão da sala de aula com a dinâmica da inclusão.

Para que inclusão educacional se torne uma realidade e que o aluno seja sujeito desse processo, além do principal beneficiado, é necessário ressignificar o que é currículo, o que

\section{POLÊM!CA $\mid$ LABORE}


entendemos por aprendizagem, fazer escolhas sobre quais conteúdos serão trabalhados, como serão ensinados e avaliados, se tais conteúdos são realmente importantes para os alunos, o número de alunos por turma e os profissionais que precisarão atuar. Além disso, como a inclusão se insere na proposta pedagógica da escola e no projeto político-pedagógico. A inclusão precisa representar um movimento político da escola como parte da sua filosofia de educação e não algo que precisa cumprir sob a forma da lei para evitar as sanções legais. Educar um aluno, seja ele qual for, não pode ser fruto do medo da punição.

\section{A mediação escolar e as indefinições sobre as formas de atuação}

De julho de 2015 a janeiro de 2016, houve um período de grande tensão entre instituições escolares, familiares e o judiciário. Muito embora a lei de inclusão tenha trazido várias modificações também positivas para as práticas escolares e nos direitos da pessoa com deficiência, um tópico ocupava a atenção neste período e foi motivo de várias disputas judiciais: a mediação escolar. Por mediador concebemos o profissional que apoia o aluno quando este não possui autonomia física, sensorial, comportamental ou cognitiva para aprender. Este aluno necessita que haja uma interlocução para entender as tarefas bem como a cronologia e regras das atividades. A nomenclatura da função "mediador" pode variar de município para município e existe uma variação extensa quando analisamos o perfil profissiográfico, bem como a experiência e a formação de cada um dos mediadores. Mas não foi nenhum desses aspectos que ocupou a atenção da sociedade no último semestre de 2015, além de várias reportagens sobre o tema na mídia. A discussão mais contundente foi sobre a responsabilidade financeira da contratação do mediador. Sem uma definição sobre a formação, funções e piso salarial, a maioria das escolas condicionava a matrícula dos alunos com necessidades educacionais especiais à presença de um mediador que deveria ser custeado pela família. A lei $\mathrm{n}^{\circ} 13.146 / 15$, dentre as suas mudanças, define que a mediação passa a ser então uma obrigação financeira e pedagógica das instituições de ensino. Como condição da permanência de seus filhos na escola "inclusiva", as famílias aceitavam esse acordo se submetendo ao risco, inclusive diante das leis trabalhistas, já que como pessoas físicas, não podiam contratar um mediador. Como pessoa física e cidadão, é permitido contratar apenas empregados domésticos. Para tentar garantir alguns acordos, as partes, famílias e mediadores elaboraram contratos de gavetas e acordos de cavalheiros, sem nenhuma proteção jurídica.

\section{POLÊM!CA $\mid$ LABORE}


Curiosamente, a mesma justiça do trabalho que não permitia a formalização da função, acatava a ação dos profissionais da mediação contra as famílias quando este vínculo chegava ao fim de forma não amigável.

A Lei Brasileira de Inclusão define parcialmente as regras sobre a contratação do mediador. Fica clara a responsabilidade da escola, mas continuam indefinidas a formação do mediador, piso salarial e regras de contratação, deixando uma abertura que poderia ser bem utilizada em forma de autonomia responsável das escolas para decidir seus projetos de inclusão, mas não tem sido esta realidade em boa parte dos casos. O cenário é confuso e diverso no pior sentido da expressão. No cotidiano das escolas encontramos mediadores que assumem a responsabilidade de assessorar vários alunos simultaneamente, fazendo com que o trabalho fique fragmentado; estagiários ${ }^{1}$, obviamente com vínculo temporário, que atuam como mediadores sem nenhuma familiaridade com o quadro da criança e mediadores que ainda são subsidiados pelas famílias por algum tipo de acordo com instituições. As escolas da rede privada alegam o impacto financeiro para descumprir a lei ou cumpri-la parcialmente, e a rede pública, também desamparada pelo Estado na providência imediata dos profissionais necessários para compor o staff da escola inclusiva, lança mão dos estagiários de licenciaturas diversas e com permanência temporária. A rotatividade de estagiários é grande e a duração curta não permite que haja aprofundamento nas relações interpessoais e na apropriação dos saberes. Ou seja, o mediador perde a sua finalidade pedagógica. A sua presença, que deveria garantir a aprendizagem e autonomia do aluno, passa a ser confundida pelo papel de acompanhante ou profissional de apoio descritas na lei $\mathrm{n}^{\mathrm{o}} 13.146 / 15^{2}$.

Por realizar a inclusão sob força da lei, dentre outros motivos, em geral, as instituições recebem o aluno que possui uma diferença em sua constituição biopsicossocial como realização de um esforço institucional, e nos discursos dos gestores encontramos afirmativas

${ }^{1}$ O vínculo do estagiário no Estado do Rio de Janeiro costuma ser de seis meses letivos e os estudantes de graduação são oriundos de licenciaturas diversas.

${ }^{2}$ A lei no 13.146/2015, no Artigo 3, Capítulos XII, XII e XIV, define e diferencia as funções de atendente pessoal, profissional de apoio e acompanhante. XII - atendente pessoal: pessoa, membro ou não da família, que, com ou sem remuneração, assiste ou presta cuidados básicos e essenciais à pessoa com deficiência no exercício de suas atividades diárias, excluídas as técnicas ou os procedimentos identificados com profissões legalmente estabelecidas; XIII - profissional de apoio escolar: pessoa que exerce atividades de alimentação, higiene e locomoção do estudante com deficiência e atua em todas as atividades escolares nas quais se fizer necessária, em todos os níveis e modalidades de ensino, em instituições públicas e privadas, excluídas as técnicas ou os procedimentos identificados com profissões legalmente estabelecidas; XIV - acompanhante: aquele que acompanha a pessoa com deficiência, podendo ou não desempenhar as funções de atendente pessoal.

\section{POLÊM!CA $\mid$ LABORE}

Polêmica - Revista Eletrônica da Uerj - Rua São Francisco Xavier, 524, $1^{\circ}$ andar

bloco D, sl.1001 • Tels.: +55 21 2334-4088 / 4087 • http://www.e-publicacoes.uerj.br/index.php/polemica/index

http://www.labore.uerj.br • laboreuerj@yahoo.com.br 
como "nossos professores não estão preparados", "nossas salas de aula não comportam um aluno com tal demanda" ou "as turmas possuem muitos alunos". Na maioria dos casos, as respostas aos pais são fruto de uma realidade. É claro que infelizmente há situações nas quais os alunos não são desejados e a recusa da matrícula não possui justificativas, contudo, muitas escolas não fariam um trabalho pedagógico a contento e, sem dúvida, como já citado em outros trabalhos, a pior das exclusões é a inclusão mal planejada e executada. Cabe explicitar que por inclusão insatisfatória entendemos o modelo no qual a matrícula é aceita, mas a permanência da criança se resume à convivência social e a aprendizagem sistemática não é concretizada (STAINBACK, 1999; SERRA, 2008). É preciso que os familiares tenham o direito da matrícula e a garantia que as instituições proverão o desenvolvimento de seus filhos. É preciso que o Estado colabore com as instituições escolares provendo recursos e apoios para que as instituições escolares se mantenham e executem um trabalho de excelência com todos os alunos (MICHELS, 2016).

\section{O reconhecimento do aluno que tem direitos à inclusão - "Tempos de Casa Verde"3}

Observamos no cotidiano das escolas inclusivas um aumento significativo de alunos especiais. Seria muito gratificante se o número expressivo representasse que estamos incluindo mais, recebendo mais alunos, sem distinção (SANTOS, 2006). Contudo, percebemos uma diversidade de diagnósticos e o encaminhamento de toda e qualquer diferença no comportamento ou nos padrões de aprendizagem. Os diagnósticos e as avaliações interdisciplinares são de extrema importância para elaborar os melhores caminhos pedagógicos, mas em boa parte das situações, o trabalho clínico poderia ser evitado se modificássemos as condutas pedagógicas. Não se trata de um retorno ao "otimismo pedagógico" e muito menos de negar que as dificuldades e transtornos existem, mas evitar a medicalização e a clínica da diferença. Nem toda agitação é $\mathrm{TDAH}^{4}$ e nem toda dificuldade para aprender a ler é dislexia ${ }^{5}$.

Existem situações nas quais o diagnóstico precoce é indispensável e resgata o desenvolvimento típico. O TEA, Transtorno do Espectro Autista é um exemplo. A literatura sobre o tema é clara: quando não detectamos e intervimos rapidamente, perdemos uma

\footnotetext{
${ }^{3}$ O termo "Casa Verde" faz alusão ao nome do Hospital Psiquiátrico da Obra "O Alienista" de Machado de Assis.

${ }_{5}^{4}$ Transtorno de Déficit de Atenção e Hiperatividade, de acordo com o DSM5.

${ }^{5}$ Transtorno Específico de Linguagem que dificulta a aprendizagem da leitura e da escrita.
}

\section{POLÊM!CA $\mid$ LABORE}


criança. Perdemos a possibilidade de ver seu desenvolvimento típico ocorrer e eliminar, ou minimizar, as dificuldades encontradas na vida (DUARTE, 2016).

Para a Lei Brasileira de Inclusão, são os alunos que precisam de apoios diferenciados:

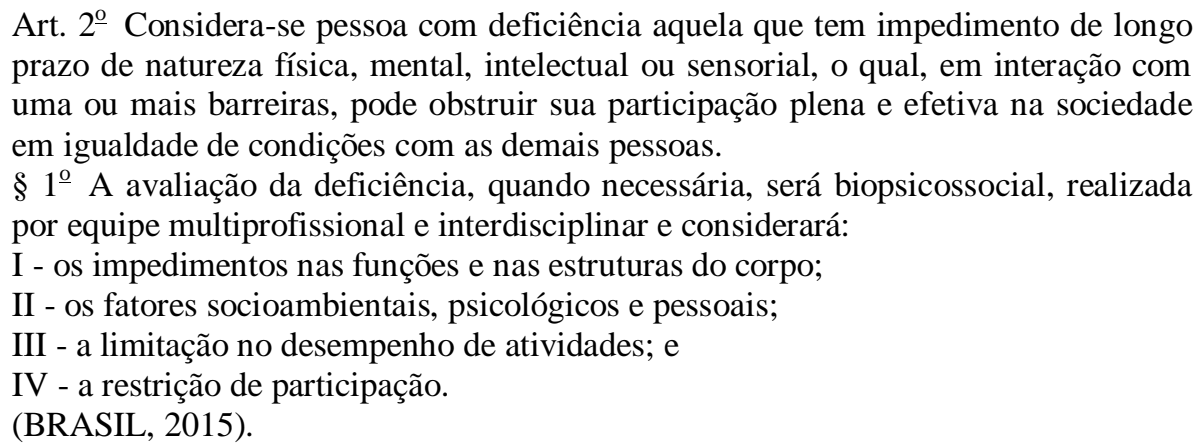

Há de se ressaltar um avanço sutil nesta delimitação. A lei em questão afirma que as avaliações serão realizadas quando necessárias. Significa que as escolas não necessitarão ter um laudo para matricular as crianças e que as avaliações, quando necessárias, devem nos servir para delinear os melhores caminhos e não para estigmatizar ou excluir os alunos. Parece haver um incômodo por parte das instituições para realizar as avaliações, mas avaliar é uma tarefa da escola. Não significa realizar diagnósticos clínicos, mas responder às perguntas: quem é esse aluno? Como ele aprende? Quais estratégias e caminhos nós teremos que providenciar para que ele se desenvolva? Todas são tarefas pedagógicas e não clínicas. $\mathrm{O}$ trabalho interdisciplinar é bem-vindo e muito necessário, a parceria com profissionais que tratam os alunos da escola é indispensável, mas não a ponto de eliminar ou ferir a autonomia da escola (DA SILVA, 2016).

\section{O desenvolvimento de práticas inclusivas}

O Plano de Atendimento Educacional Especializado pode ser um importante norteador para a promoção da aprendizagem dos alunos que necessitam de atendimento especializado. $\mathrm{O}$ plano educacional não pode ser um documento isolado, destacado da realidade educacional. É necessário que ele represente o projeto político-pedagógico da instituição e os princípios da inclusão. Antes de ser qualquer burocracia, deve representar as metas a alcançar com cada aluno, suas características e o quanto necessitará de adaptações para a acessibilidade ao currículo (VILARONGA, 2016).

\section{POLÊM!CA $\mid$ LABORE}


A lei $\mathrm{n}^{\circ}$ 13.146/2015 afirma que o Poder Público deverá acompanhar todo o processo pedagógico. Queremos crer que esse acompanhamento seja uma assessoria aos profissionais de educação com formação continuada de qualidade e acompanhamento em forma de consultoria e não de fiscalização (SANTOS, 2016).

É necessário que as escolas possam contar com profissionais de áreas diversas que colaborarem com o cotidiano dos professores e com a qualidade do que é oferecido aos alunos.

\section{Considerações finais}

Ao finalizarmos este trabalho, concluímos que a discussão da educação na forma jurídica não representa o melhor caminho. A inclusão sob a força da lei impõe uma realidade que nem sempre produz os melhores resultados pedagógicos. Houve sem dúvida, ganhos, em especial na definição do custeio da mediação que deixa de onerar as famílias, mas falta a definição sobre o perfil do mediador e condições trabalhistas.

$\mathrm{Na}$ identificação das necessidades especiais, observamos uma leitura equivocada sobre quem deve ser beneficiado, uma vez que uma amplitude tão generalizada pode ressaltar ainda mais uma tendência ao estigma e a negação das diferenças como parte integrante da condição humana.

Percebemos que também é necessário que o Estado apoie melhor as instituições de ensino com recursos tecnológicos, matérias de tecnologia assistiva, formação continuada e assessoramento às famílias. Cada vez mais entendemos a inclusão como fruto da articulação de Políticas Públicas em parceria com profissionais de educação e familiares envolvidos.

\section{Referências}

BRASIL. Lei n 13.146 , de 06 de julho de 2015. Institui a Lei Brasileira de Inclusão da Pessoa com Deficiência (Estatuto da Pessoa com Deficiência). Diário Oficial [da] República Federativa do Brasil, Brasília, DF, 7 jul. 2015.

DA SILVA, Suzana Sirlene; CARNEIRO, Relma Urel Carbone. Inclusão escolar de alunos público-alvo da educação especial: como se dá o trabalho pedagógico do professor no ensino fundamental I? Revista IberoAmericana de Estudos em Educação, v. 11, n. 2, p. 935-955, 2016.

DUARTE, Cíntia Perez; SCHWARTZMAN, José Salomão; MATSUMOTO, Michele Sayulli; BRUNONI, Decio. Diagnóstico e Intervenção Precoce no Transtorno do Espectro do Autismo: Relato de um caso. In: CAMINHA, Vera Lúcia; HUGUENIN, Julliane; ASSIS, Lúcia M. de; ALVES, Priscila Pires. Autismo Vivências e Caminhos. São Paulo: Blucher, 2016.

\section{POLÊM!CA $\mid$ LABORE}


MICHELS, Maria Helena. Gestão, Formação Docente e Inclusão: eixos da reforma educacional brasileira que atribuem contornos à organização escolar. Revista Brasileira de Educação, v. 11, n. 33, p. 406-423, 2006.

STAINBACK, Susan; STAINBACK William. Inclusão - Um guia para educadores. Porto Alegre: Editora Artes Médicas Sul, 1999.

SANTOS, Mônica Pereira dos; PAULINO, Marcos Moreira (orgs). Inclusão em Educação - Culturas, políticas e práticas. São Paulo: Cortez, 2006.

SANTOS, Wederson. Deficiência como restrição de participação social: desafios para avaliação a partir da Lei Brasileira de Inclusão. Revista Ciência \& Saúde Coletiva [online], v. 21, n. 10, p. 3007-3015, 2016.

SERRA, Dayse Carla Genero. Entre a esperança e o limite: um estudo sobre a inclusão de alunos com autismo em classes regulares. Psicologia Clínica, Rio de Janeiro, v. 21. n. 1, p. 488, 2009.

VIRALONGA, Carla Ariela Rios; MENDES, Enicéia Gonçalves. Ensino colaborativo para o apoio à inclusão escolar: práticas colaborativas entre os professores. Revista Brasileira de Estudos Pedagógicos [online], v. 95, n. 239, p.139-151, jan./abr. 2014.

Recebido em: 07/11/2016.

Aceito em: 30/12/2016.

\section{POLÊM!CA $\mid$ LABORE}

Polêmica - Revista Eletrônica da Uerj - Rua São Francisco Xavier, 524, $1^{\circ}$ andar 